\title{
AVALIAÇÃO DE COMPACTAÇÃO DO SOLO NA CANA-DE-AÇUCAR UTILIZANDO PENETRÔMETRO
}

\author{
Matheus Teixeira de Souza ${ }^{1}$, Ricardo Alexandre Lambert ${ }^{2}$.
}

${ }^{1}$ Graduando em Agronomia pelo Instituto Luterano de Ensino Superior de Itumbiara-

GO - ILES/ULBRA (matheus_0791@hotmail.com) Itumbiara-GO, Brasil.

${ }^{2}$ Professor Doutor do Instituto Luterano de Ensino Superior de Itumbiara-GO -

ILES/ULBRA.

Recebido em: 08/04/2016 - Aprovado em: 30/05/2016 - Publicado em: 20/06/2016 DOI: 10.18677/Enciclopedia_Biosfera_2016_012

\begin{abstract}
RESUMO
As atuais técnicas de manejo da cultura da cana-de-açúcar utilizam uma série de etapas de revolvimento do solo no plantio, com o uso de arados, grades pesadas e subsoladores, o que pode apresentar fatores que influenciam em sua resistência. Sendo assim, objetivou-se avaliar a resistência do solo à penetração na cultura da cana de açúcar, em diferentes idades (cana de $1^{\circ}$ ao $8^{\circ}$ corte). $O$ trabalho foi desenvolvido na Fazenda Alvorada, no município de Araporã-MG, avaliando-se a resistência à penetração em diferentes tipos de corte. $O$ delineamento foi conduzido em esquema fatorial triplo com oito cortes $\left(1^{\circ}, 2^{\circ}, 3^{\circ}, 4^{\circ}, 5^{\circ}, 6^{\circ}, 7^{\circ}\right.$ e 89 , dois locais de coleta (linha e entrelinha) e três profundidades (0-15, 15-30 e 30-45 cm), logo sendo 48 tratamentos com cinco repetições, perfazendo um total de 240 unidades experimentais, sendo utilizado um penetrômetro de impacto, onde se considerou a profundidade após a $1^{\circ}$ batida do êmbolo. Para análise estatística foi realizada a anava e quando significativo feito teste de Tukey a $1 \%$ de probabilidade. De acordo com os dados obtidos observou-se que houve algumas variações significativas entre as interações entre cortes, profundidade e entre cortes e local para avaliação de resistência a $1 \%$ de probabilidade. Nota-se que o local em que foi realizado experimento (linha e entre linha) não diferiu estatisticamente, sendo que a profundidade e idade da cana ( $1^{\circ}$ ao $8^{\circ}$ corte) foram cruciais para dar significância ao teste realizado. De acordo com o presente estudo, observa-se a necessidade de estudos adicionais sobre a resistência à penetração na cultura da cana de açúcar em condições adversas do solo.
\end{abstract}

PALAVRAS-CHAVE: cortes, latossolo, resistência à penetração.

\section{SOIL COMPRESSION ASSESSMENT IN CANE SUGAR USING PENETROMETER}

\begin{abstract}
Current techniques of crop management of sugarcane using a series of steps of soil disturbance at planting, with the use of plows, harrows and heavy subsoilers, which may present factors that influence its resistance. Thus, this study aimed to evaluate the soil penetration resistance in the culture of sugar cane, at different ages (cane 1st to 8th cut). The study was conducted at Fazenda Alvorada, in the municipality of Araporã-MG, evaluating resistance to penetration in different cuts. The experiment
\end{abstract}


was conducted in triple factorial design with eight cuts (1st, 2nd, 3rd, 4th, 5th, 6th, 7th and 8th), two collection points (line and spacing) and three depths (0-15, 15-30 and $30-45 \mathrm{~cm}$ ), then with 48 treatments with five repetitions, a total of 240 experimental units, using a penetrometer impact, which was considered the depth after the 1st piston beat. Statistical analysis was performed by anova and when significant achievement Tukey test at $1 \%$ probability. According to the data obtained it was observed that there were some significant differences between interactions between cuts, cutting depth and between local and for evaluation of resistance to $1 \%$ probability. Note that if the place where it was performed experiment (between line and line) did not differ statistically, and the depth and cane age (1st to 8th cut) were crucial to give significance to the test performed. According to this study, there is a need for further study on the penetration resistance in the culture of sugar cane in adverse soil conditions.

KEYWORDS: cutting, latosol, penetration to resistance.

\section{INTRODUÇÃO}

Atualmente o Brasil vem se destacando como o maior produtor mundial de cana-de-açúcar, estima-se uma produção de 658,8 milhões de toneladas na safra de 2013/14 em uma área plantada de mais de 8,81 milhões de hectares que representa uma média de $74.769 \mathrm{Kg} / \mathrm{ha}$, sendo o estado de São Paulo considerado o maior produtor nacional com mais de $51,7 \%$ de área plantada (CONAB, 2014). Colocando o nosso país em uma posição de destaque no que se diz respeito à produção de energia renovável, principalmente nos setores de bioenergia e biocombustíveis (HOLANDA, 2012).

A utilização inadequada do solo pode trazer uma série de alterações e fatores importantes para o seu agravamento, causado muitas vezes pelo uso de máquinas e implementos agrícolas. A compactação do solo promove a concentração das partículas sólidas em decorrência da expulsão do ar gerado pela redução de sua porosidade, de forma que este processo reduz o seu volume e aumenta sua densidade provocada por uma carga externa, resultando em aumento na resistência do solo à penetração, como também na redução da permeabilidade do solo (MASIERO, 2013).

De acordo com SILVA et al. (2011), o tráfego intensivo de máquinas é o principal responsável pelo aumento da densidade e resistência do solo, diminuição da macro porosidade e condutividade hidráulica o que resulta na compactação do solo e alterando o meio onde o sistema radicular desenvolve-se.

No solo, existe uma infinidade de fatores correlacionados a características físicas, químicas e biológicas que controlam os processos e aspectos relacionados à a variação no tempo e no espaço. Qualquer modificação no solo pode alterar diretamente a estrutura e a atividade biológica e, consequentemente, a fertilidade, podendo reduzir as características de qualidade do solo e produção da cultura (SGOBERO, 2014). O solo é considerado um sistema complexo, resultado de interações de fatores geológicos, topográficos e climáticos, entre outros, que juntos formam indicadores que o caracterizam em seus atributos.

O tráfego intenso de máquinas e implementos agrícolas cada vez mais pesados e constante, leva uma preocupação a mais aos produtores no que diz respeito aos efeitos da estrutura física do solo e possíveis danos à cultura. Alguns autores atribuem a passagem intensa do maquinário ao aumento da compactação do solo, que pode promover perda na produção da cultura devido à limitação da 
infiltração de água, trocas gasosas entre raiz, solo e atmosfera e o desenvolvimento radicular das plantas (ROSSINI, 2014)

A caracterização das camadas compactadas e dos atributos do solo em relação às propriedades físicas, como por exemplo, a densidade, porosidade, umidade e capacidade de retenção e infiltração da água, é de extrema importância para o planejamento de manejo de produção (CUNHA, 2012).

Sendo assim, a compactação do solo é um fator limitante para o aumento da produtividade da cana-de-açúcar, causando uma alteração na porosidade do solo e reduzindo a quantidade de água disponível em até $100 \%$. Tendo como consequências deste manejo inadequado a queda na produtividade das culturas e a degradação ambiental do solo.

Diante do exposto, o objetivo do trabalho foi avaliar a resistência do solo à penetração na cultura da cana de açúcar, em diferentes idades (cana de $1^{\circ}$ ao $8^{\circ}$ corte).

\section{MATERIAL E MÉTODOS}

O trabalho foi desenvolvido na Fazenda Alvorada, cujas coordenadas geográficas são 1826'23" de latitude sul e 4911'16" de longitude oeste, situado a 455 metros de altitude, na rodovia BR 452 no município de Araporã- MG. O clima da região é tropical, com predominância de mais chuvas no verão que no inverno, a temperatura média anual é de $24,4^{\circ} \mathrm{C}$, com $1140 \mathrm{~mm}$ de pluviosidade média anual, evidencia-se que o mês de agosto é considerado o mais seco com índice de pluviosidade de $2 \mathrm{~mm}$, enquanto o mês de janeiro possui uma média de $229 \mathrm{~mm}$, a maior precipitação do ano no acumulado (IBGE, 2014).

O solo em estudo foi classificado como Latossolo Vermelho distrófico de textura média, conforme análise do solo realizada pelo laboratório do ILES/ULBRA. Para a realização do experimento foi utilizada área cultivada com cana-de-açúcar das variedades CTC 4, CTC 24 e IAC-SP 955000, sendo que em cada área foi avaliado a resistência à penetração do solo.

O experimento foi conduzido em esquema fatorial triplo, com oito cortes $\left(1^{\circ}\right.$, $2^{\circ}, 3^{\circ}, 4^{\circ}, 5^{\circ}, 6^{\circ}, 7^{\circ}$ e 89 e três profundidades ( 0-15, 15-30 e 30-45 cm), com dois locais de coleta (linha e entrelinha da cana), logo sendo 48 tratamentos, com cinco repetições, perfazendo um total de 240 unidades experimentais. Cada unidade experimental foi escolhida ao acaso, perfazendo toda a área, com um total de 122,25 ha.

As avaliações foram realizadas nas datas: 13/02/15 ( $1^{\circ}$ e $2^{\circ}$ corte), 14/02/15

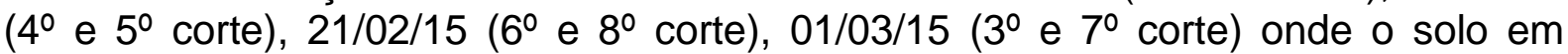
estudo se encontrava próximo à capacidade de campo, com um total acumulado de precipitação de $83 \mathrm{~mm}$ dentro dos dias analisados.

Para a avaliação da resistência mecânica à penetração, foi utilizado um penetrômetro de impacto, onde se considerou a profundidade após a $1^{\circ}$ batida do êmbolo. O penetrômetro utilizado é composto de uma haste metálica com o cone na sua extremidade, sendo o corpo metálico utilizado para a batida $(\mathrm{M}=4 \mathrm{~kg})$. Durante a batida a energia potencial do corpo metálico armazenada pela elevação a uma altura de $40 \mathrm{~cm}$ é usada para inserir a haste com o cone no solo. A profundidade de penetração obtida pela aplicação de uma quantidade de energia constante é usada para medir a resistência à penetração do solo.

A resistência à penetração pode ser determinada considerando que a energia potencial do corpo metálico é convertida em trabalho de penetração do cone. A energia potencial total do sistema após o impacto é igual à energia potencial do corpo metálico a uma altura $h(m)$, mais a energia potencial da distância da 
penetração $x(\mathrm{~m})$. Considerando a perda de energia devido ao impacto e uma colisão inelástica do corpo metálico, obtêm-se a seguinte expressão: $F x=(M \times g \times$ h) $\times f+(M+m) \times g \times x$, onde $F(N)$ é a força de penetração, $x(m)$ é a distância de penetração após cada impacto, $\mathrm{M}(\mathrm{kg})$ e $\mathrm{m}(\mathrm{kg})$ a massa do corpo metálico de impacto e do restante do penetrômetro (hastes, cones e demais peças), respectivamente e $\mathrm{g}\left(\mathrm{m} \mathrm{s}^{-1}\right)$ é a aceleração da gravidade.

Foi realizada a análise de variância (ANAVA) e quando significativo foi feito teste de Tukey a $1 \%$ de probabilidade, utilizando o software estatístico SisvarSistema de Análise da variância (FERREIRA, 2000).

\section{RESULTADOS E DISCUSSÃO}

$\mathrm{Na}$ Tabela 1 são apresentados os resultados relacionados a avaliação de resistência à penetração para os diferentes idades de cortes na cana de açúcar. Observa-se que houve algumas variações significativas para: cortes, profundidade e entre corte $\mathrm{x}$ local, para avaliação de resistência ao nível significativo de $1 \%$ de probabilidade.

TABELA 1- Resumo da análise de variância para avaliação de resistência à penetração em Araporã- MG.
F.V
G.L
Quadrado Médio

Cortes

Local

Profundidade

Cortes * Local

Cortes * Profundidade

1

2

7

14

Cortes * Local * Profundidade

14

Local * Profundidade

2

$$
\begin{array}{r}
24,14^{* *} \\
8,94^{\text {ns }} \\
184,86^{* *} \\
8,98^{* *} \\
2,57^{\text {ns }} \\
3,40^{\text {ns }} \\
4,95^{\text {ns }}
\end{array}
$$

\begin{tabular}{lc}
\hline Total & 47 \\
\hline $\mathrm{CV}(\%)$ & 26,73 \\
\hline
\end{tabular}

: significativo ao nível de $1 \%$ de probabilidade

ns. não significativo

Através da análise da Tabela 1 nota-se que o local em que foi realizado experimento (linha e entre linha da cana-de-açúcar) não diferiu estatisticamente, sendo que a profundidade e idade da cana (1ำ ao $8^{\circ}$ corte) foram cruciais para dar significância ao teste realizado.

$\mathrm{Na}$ Tabela 2 observou-se uma diferença nas profundidades analisadas entre os valores médios em estudos de resistência a penetração. 
TABELA 2 - Valores médios para avaliação de resistência à penetração em diferentes profundidades analisados em Araporã- MG.

\begin{tabular}{ll}
\hline & Médias dos Tratamentos \\
\hline Profundidade $(\mathrm{cm})$ & Resistência à Penetração $(\mathrm{kpa})$ \\
\hline
\end{tabular}

$\begin{array}{rl}0-15 & 4,44 \mathrm{a} \\ 15-30 & 6,74 \mathrm{~b} \\ 30-45 & 7,17 \mathrm{~b}\end{array}$

Médias seguidas por letras iguais não diferem ente si pelo teste de Tukey a 1\% de significância.

No que tange a profundidade camada de $15-45 \mathrm{~cm}$, os valores médios de Resistência à Penetração (RP) tenderam a apresentar uma variação muito grande em relação a $0-15 \mathrm{~cm}$. É importante elucidar que a camada significativa muito diferente na avaliação das pressões sobre o solo é a camada de $0-15 \mathrm{~cm}$ de profundidade, em que apresentou diferença significativa entre as outras profundidades, com valor médio de RP de 4,44 Kpa.

Esses dados assemelham-se a resultados verificados por BRAIDA et al., (2006) que em estudos observaram que a camada de $0-10 \mathrm{~cm}$ de profundidade apresentam os menores valores de resistência a penetração, em todas as áreas e safras, fato este possivelmente acarretados pela carga sobreposta nesta camada pelas máquinas nos resíduos da cana-de-açúcar, mencionando ainda que um alto teor de matéria orgânica na camada superficial edáfica pode contribuir também na redução da compactação do solo.

Reportando a Tabela 2, é possível observar o aumento da Resistência à Penetração à medida que vai se aprofundando no perfil do solo, sendo que os maiores níveis de RP estão na profundidade de até $30-45 \mathrm{~cm}(7,17 \mathrm{Kpa})$; cabe ressaltar que a camada de $0-15 \mathrm{~cm}$ os valores são baixos, em relação as faixas das demais camadas em estudo.

Esses resultados estão de acordo com os encontrados por ROSOLEM et al. (2012) em que houve tendência ao aumento de RP nas camadas mais profundas do solo, entre $20-50 \mathrm{~cm}$, embora as médias $15-30 \mathrm{~cm}$ e $30-45 \mathrm{~cm}$ tenham sido estatisticamente iguais, entre as profundidades ocorrem valores menores nas camadas superiores.

Apesar dos valores de RP em todas as profundidades não terem apresentado diferença estatística, onde o melhor resultado obtido foi na camada de 0-15 cm, os mesmos se encontram no nível crítico para a cultura $(2,0 \mathrm{KPa})$, o que indica maior compactação, o que pode estar relacionado ao fluxo de veículos no processo de colheita da cana-de-açúcar (OLIVEIRA et al., 2008).

Esclarece-se que o tipo de solo e o número de cortes influenciam os resultados que se pode obter com o manejo da cultura de cana-de-açúcar, uma vez que o tráfego de equipamentos neste sistema de produção é intenso, além de se tratar de uma cultura semiperene tendo em média cinco a oito cortes antes da renovação do canavial (CARVALHO, 2008).

Nessa ótica, como o número de cortes da cana-de-açúcar pode afetar diretamente a capacidade de resistência à penetração, segue dados da avaliação de $\mathrm{RP}$ em diferentes cortes. No que se refere à RP em função dos cortes a cana-deaçúcar nota-se uma correlação, com maior diferença significativa nos $3^{\circ}$, $5^{\circ}$ e $7^{\circ}$ 
cortes, denotando-se uma maior RP. A cana-de-açúcar de $2^{\circ}$ e $4^{\circ}$ corte apresentaram os menores valores, diferindo dos demais. Nota-se que o $1^{\circ}$ corte não diferiu estatisticamente do 6으 e $8^{\circ}$ corte respectivamente (Tabela 3).

TABELA 3 - Valores médios para avaliação de resistência à penetração em diferentes tipos de corte analisados em Araporã- MG.

\begin{tabular}{|c|c|c|}
\hline \multirow[b]{2}{*}{ Tratamentos } & \multicolumn{2}{|c|}{ Médias dos } \\
\hline & Resistência & a $P$ \\
\hline $2^{\circ}$ corte & $4,96 \mathrm{a}$ & \\
\hline $4^{\circ}$ corte & $5,21 \mathrm{a}$ & \\
\hline $1^{\circ}$ corte & 5,31 a & $b$ \\
\hline $8^{\circ}$ corte & 6,54 & b c \\
\hline $6^{\circ}$ corte & 6,58 & $\mathrm{bc}$ \\
\hline $3^{\circ}$ corte & 6,70 & C \\
\hline $5^{\circ}$ corte & 6,93 & C \\
\hline $7^{\circ}$ corte & 7,32 & C \\
\hline
\end{tabular}

Médias seguidas por letras iguais não diferem ente si pelo teste de Tukey a 1\% de significância.

CENTURION (2007) observou altos valores de resistência o que demonstra maior compactação, provavelmente devido ao manejo do solo inadequado e ao tráfego intenso das máquinas. Além disso, REINERT (2008) considera ainda que o equilíbrio da estrutura do solo apresentada entre $03^{\circ}$ e $08^{\circ}$ corte é significativo, sendo que muitos autores ponderam que a maior alteração na estrutura edáfica ocorre no primeiro contato com os implementos de máquinas que aconteceu no primeiro corte.

A condição de RP variou praticamente da mesma maneira para ambas as idades da cana-de-açúcar, sendo que entre cada ciclo, apresentou amplitudes diferentes. Complementando, FELIPE (2008) esclarece que as alterações físicas na estrutura do solo ao longo do ciclo anual podem não estar associadas apenas ao tráfego de máquinas, mas também a fenômenos que afetam a área de modo amplo, como ciclo de umedecimento e secamento, rearranjo natural das partículas, desenvolvimento dos microrganismos do solo e estabilização da matéria orgânica.

O aumento da RP com o aumento da profundidade e a idade do corte, pode estar relacionado com as condições anteriores do solo, sendo que a cultura de canade-açúcar apresenta inúmeras operações mecanizadas sobre a superfície do solo, fazendo com que seja trafegada várias vezes a cada ciclo de produção, com condições diversas de teor de água no solo, o que consequentemente altera a RP (MICHELAZZO \& BRAUNBECK, 2007).

Outra interação que merece destaque na avaliação de compactação do solo utilizando penetrômetro é o local em que se analisa a RP no caso, linha e entrelinha da cana-de-açúcar, de acordo com o corte (Tabela 4). 
TABELA 4 - Valores médios para avaliação de resistência à penetração em diferentes tipos de corte analisados (linha e na entre linha), em Araporã- MG.

\begin{tabular}{|c|c|c|c|c|c|}
\hline \multirow[b]{2}{*}{ Tratamentos } & \multicolumn{5}{|c|}{ Médias dos Tratamentos (Resistencia a Penetração - Kpa) } \\
\hline & \multicolumn{2}{|l|}{ Linha } & \multicolumn{2}{|l|}{ Entre linha } & \multirow{2}{*}{$\begin{array}{c}\text { Média } \\
5,31\end{array}$} \\
\hline $1^{\circ}$ corte & $4,96 a b$ & $A$ & $5,66 \mathrm{a}$ & A & \\
\hline $2^{\circ}$ corte & $4,49 a$ & A & $5,43 a$ & A & 4,96 \\
\hline $3^{\circ}$ corte & 7,30 & A & $6,12 \mathrm{a}$ & A & 6,71 \\
\hline $4^{\circ}$ corte & $4,67 \mathrm{a} \mathrm{b}$ & A & $5,75 a$ & A & 5,21 \\
\hline $5^{\circ}$ corte & 7,12 & A & $6,73 a b$ & A & 6,92 \\
\hline 6으 corte & 6,80 & A & $6,37 \mathrm{a}$ & A & 6,58 \\
\hline $7^{\circ}$ corte & 6,18 a b c d & A & $8,47 \quad b$ & B & 7,32 \\
\hline $8^{\circ}$ corte & 6,50 b c d & A & $6,57 \mathrm{a}$ & A & 6,48 \\
\hline Média & 6,00 & & 6,37 & & \\
\hline
\end{tabular}

Médias seguidas por letras minúsculas na coluna iguais não diferem ente si pelo teste de Tukey a $1 \%$ de significância. E médias com letras maiúsculas iguais na linha não diferem entre si pelo teste de Tukey a 1 \% de significância.

Nota-se na Tabela 4 que ocorreram maiores valores de RP na linha de canade-açúcar no $3^{\circ}$ e $5^{\circ}$ corte respectivamente, diferenciando estatisticamente dos $2^{\circ}$, $4^{\circ}$ e $1^{\circ}$ cortes, sendo que 0 efeito do tráfego pode atingi-las com a mesma intensidade. E na entrelinha observou-se maior RP na cana de $7^{\circ}$ corte, sendo que $1^{\circ}$ corte obteve a menor média, semelhante aos dados encontrados na linha da cana-de-açúcar.

Foram observadas também diferenças significativas em relação aos locais (linha e entrelinha da cana), que pode ter uma relação direta com o espaçamento utilizado nas entre linhas adotado nesta área, o que confere com resultados encontrados por CARVALHO et al. (2008) que mencionam a interação dos valores médios de RP, entre local de amostragem e o ciclo da cultura, em camadas superficiais ou mais profundas.

Observaram-se menores valores de RP na linha da cultura, onde o $2^{\circ}, 4^{\circ} \mathrm{e}$ $1^{\circ}$ cortes, foram menos influenciados pelo tráfego, não se diferindo estatisticamente. $\mathrm{Na}$ idade de $7^{\circ}, 8^{\circ}$ e $6^{\circ}$ cortes, pode-se inferir que o aumento da idade dos cortes permitiu maior RP na linha da cultura, que pode ser resultado do deslocamento de máquinas ocorrido nas linhas de tráfego, influenciando a compactação das camadas mais profundas da linha (Tabela 4).

Não é possível mencionar que a resistência à penetração aumente em acordo com o ciclo e/ou corte da cana-de-açúcar, conforme foi observado nos estudos de OLIVEIRA et al., (2008), pois nesse caso o $3^{\circ}$ corte teve uma maior RP em relação as demais idades da cana-de-açúcar, com isso, o resultado não seguiu a hipótese de que a resistência mecânica do solo à penetração aumente proporcionalmente ao número de corte.

Em consonância, CARVALHO et al., (2008) ressaltam que o desenvolvimento do sistema radicular da cana-de-açúcar, pode comprometer sua produtividade em cortes sucessivos, o que não indica que a cana de $8^{\circ}$ corte vai ter uma maior RP. Os baixos valores encontrados de RP podem estar associados à subsolagem em profundidade na linha da cana, haja vista que esse processo gera o rompimento das camadas compactadas em profundidade. Bem como o aumento da 
matéria orgânica adicionada através de adubação orgânica (composto de torta de filtro) e palhada da safra anterior, podendo inferir em aumento da elasticidade do solo, ocasionando em baixos valores de compactação. BRAIDA et al. (2008), afirmam que através do aumento da matéria orgânica e adição de resíduos culturais ao solo, pode-se aumentar a elasticidade do solo, podendo reduzir a suscetibilidade à compactação.

FERREIRA et al., (2009) esclarecem que os maiores valores de resistência do solo à penetração é um indicativo de maior densidade do solo e, portanto menor porosidade, resultando em baixa capacidade de infiltração da água, menor taxa de armazenamento de água e elevação do escoamento superficial podendo acarretar degradação no solo.

Assim, nota-se que a idade da cana, de acordo com corte ( $1^{\circ}$ a $8^{\circ}$ ) não influenciou a resistência à penetração, sendo que na entrelinha da cana-de-açúcar foi verificado maior índice de RP, o que possibilita inferir que o solo está mais compactado, o que influencia diretamente na produtividade da cultura.

\section{CONCLUSÕES}

Para as condições distintas em que este experimento foi realizado, foi possível concluir que notou-se a ocorrência de resistência a penetração no solo, nas camadas a partir de $15 \mathrm{~cm}$ de profundidade. Observou-se ainda que para a cana de $7^{0}$ corte, houve maior resistência à penetração na entrelinha, do que os dados encontrados na linha da cana-de-açúcar.

Portanto, não tem como afirmar se os diferentes cortes em que a cana foi submetida contribuiu para a resistência a penetração.

De acordo com o presente estudo, observa-se a necessidade de estudos adicionais sobre a resistência do solo a penetração na cultura da cana de açúcar em condições adversas, como por exemplo, diferentes umidades e tipos de solo.

\section{AGRADECIMENTOS}

Aos proprietários da Fazenda Alvorada, localizada em Araporã-MG pela disponibilidade no desenvolvimento desse trabalho.

\section{REFERÊNCIAS}

BRAIDA, J. A.; REICHERT, J. M.; VEIGA, M.; REINERT, D. J. Resíduos vegetais na superfície e carbono orgânico do solo e suas relações com a densidade máxima obtida no ensaio Proctor. Revista Brasileira de Ciência Solo, v.30, n.1, p. 605-614, 2006. Disponível em: <http://www.scielo.br/scielo.php?script=sci_arttext\&pid=S1415$43662010000200003>$ doi: S1415-43662010000200003.

BRAIDA, J.A.; REICHERT, J.M.; REINERT, D.J.; SEQUINATTO, L. Elasticidade do solo em função da umidade e do teor de carbono orgânico. Revista Brasileira de Ciência do Solo, v.32, p.477-485, 2008.

CARVALHO, L. A.; NETO, V. J. M.; SILVA, L. F.; PEREIRA, J. G. et al. Resistência mecânica do solo à penetração (RMP) sob cultivo de cana-de-açúcar, no município de Rio Brilhante- MS. Revista Agrarian. v. 7, n. 1, p. 07-22, 2008. Disponível em: < http://www.scielo.br/scielo.php?script=sci_arttext\&pid=S0034-737X2013000100003 > doi: S0034-737X2013000100003. 
CENTURION, J. F.; SILVA, A. P.; MATOS, L. I. et al. Comparação de penetrômetros na avaliação da compactação de latossolos. Engenharia Agrícola. v.27, n.1, p.146151, $2007 . \quad$ Disponível em: <http://www.anais.ueg.br/index.php/sineep/article/download/723/1242> doi: $10.1080 / 10934529.2013 .815503$

CONAB - Companhia Nacional de Abastecimento. Acompanhamento safra Brasileira. cana-de-açúcar, v. 1 - Safra 2014/15, n.1 - Primeiro Levantamento, Brasília, abr 2014, p. 1-20. Disponível em: <http://www.conab.gov.br/OlalaCMS/uploads/arquivos/14_04_15_15_44_37_boletim _cana_portugues_-_10_lev_-_14.pdf>.

CUNHA, J. P. A R.; VIEIRA, L. C.; MAGALHÃES, A. C.; Resistência mecânica do solo à penetração sob diferentes densidades e teores de água. Engenharia na Agricultura,Viçosa v.10, n.1-4, Jan./Dez., p.1-7, 2012. Disponível em: $<$ http://repositorio.unesp.br/bitstream/handle/11449/113781/000800564.pdf?sequenc $\mathrm{e}=1>$ doi: $11449 / 13781000800564$.

FELIPE, D. C. Produtividade da cana-de-açúcar (saccharum oficcinarum) submetida a diferentes épocas de plantio e a adubação mineral. AreiaPB:UFPB/CCA, 2008.

FERREIRA, D. F. Análises estatísticas por meio do SISVAR para Windows versão 4.0. Lavras. 69p. 2000.

FERREIRA, M. J. et al. Avaliação da regeneração natural em nascentes perturbadas no município de Lavras, MG. Ciência Florestal, Santa Maria, v. 19, n.2, p. 109-129, 2009.

Disponível em:

http://www.conhecer.org.br/enciclop/2012a/ambientais/avaliacao\%20da\%20regenera cao.pdf> doi: S1215-34772010000500009.

HOLANDA, L. A. Resposta varietal da cana-de-açúcar à deficiência hídrica, durante o desenvolvimento inicial em um latossolo vermelho distroférrico. 2012, f.80. Dissertação ( Mestrado em Agronomia/ Irrigação e Drenagem apresentada a faculdade de Ciências Agronômicas da Unesp - Campus de Botucatu), Botucatu 2012, p.06.

IBGE. Município de Araporã- MG. 2014. Disponível em: $<$ http://cidades.ibge.gov.br/painel/painel.php?lang=\&codmun=316960\&search=minas geraisarapora|infograficos:-dados-gerais-do-municipio.> Acesso em 12out. 2015.

MASIERO, F. C. Produtividade e compactação do solo em diferentes ciclos anuais da cultura de cana-de-açúcar. 2013, 96 f. Tese (Doutorado em Agronomia/ apresentada à Faculdade de Ciências Agronômicas da UNESP - Campus de Botucatu, Energia na Agricultura ), Botucatu 2013, p.14-15.

MICHELAZZO, M. B.; BRAUNBECK, O. Tráfego controlado na mecanização da cana-de-açúcar. Campinas. Anais...Campinas: UNICAMP, 2007. 
OLIVEIRA, A. S.; COELHO, M. F.; FAULIN, M. S. A. R.; SALVI, J. V.; MOLIN, J. P. Variabilidade espacial da compactação do solo nas linhas de cultivo e de tráfego em cana-de- açúcar. III Congresso Brasileiro de Agricultura de Precisão, CONBAP Piracicaba, 2008.

ROSSINI, D. B. Resistência mecânica à penetração em latossolo vermelho após sucessivos cortes mecanizados de cana-de-açúcar, 2014, 83 f. Dissertação (Mestrado em Agronomia/ Produção Vegetal apresentada a faculdade de Ciências Agrárias e Veterinárias - UNESP, Campus de Jaboticabal), Jaboticabal 2014, p.0102.

ROSOLEM, C. A.; FERNANDEZ, E. M.; ANDREOTTI, M.; CRUSCIOL, C. A. C. Crescimento radicular de plântulas de milho afetado pela resistência do solo à penetração. Pesquisa agropecuária brasileira, Brasília, v.34, n.5, p.821-828, maio, 2012.

em: $<w w w . p e r i o d i c o s . u f g d . e d u . b r / i n d e x . p h p / a g r a r i a n / a r t i c l e / v i e w F i l e / . . . / 1914>\quad$ doi: S1415-43662010000200007.

SGOBERO, W.L. Avaliação de atributos físicos do solo submetidos a diferentes tipos de manejo. 2014, f. 20. Monografia apresentada ao curso de agronomia do Instituto Luterano de Ensino Superior - ULBRA, Itumbiara, p. 05.

SILVA, G. da; CAPPELLI, N. L.; UMEZU, C. K. Métodos probabilístico e determinístico para diagnóstico da necessidade de subsolagem de solos. Engenharia Agrícola, Jaboticabal, v.24, n.1, p.130-141, jan/abril, 2011. Disponível em: $\quad<h t t p: / / w w w . s c i e l o . b r / s c i e l o . p h p ? s c r i p t=s c i \_a r t t e x t \& p i d=S 0104-$ 77602012000400010> doi: S0104-77602012000400010 